\title{
Reply to correspondence letter: Is pro-adrenomedullin more useful marker in hospitalized infants with sepsis?
}

\author{
Javier Benito-Fernández
}

Received: 6 August 2013 / Accepted: 6 August 2013 / Published online: 16 August 2013

(C) Springer-Verlag Berlin Heidelberg 2013

Dear Editor,

We have read with great interest the editorial letter entitled "Is pro-adrenomedullin more useful marker in hospitalized infants with sepsis?" In this letter, the authors consider that the lack of usefulness of pro-adrenomedullin as diagnostic tool for detecting severe bacterial infection in febrile infants found in our study [1] may be mainly due to the time profile of this biomarker. In contrast to our results, they found proadrenomedullin very useful in the early detection of neonatal sepsis [2] and so they suggest that this biomarker could be only useful in the close follow-up of hospitalized patients.

While we agree with some of their comments, we disagree with the opinion that the time at which the markers were measured could play a role in the interpretation of the results of both studies. As it is mentioned in the discussion of our article, we think that the clinical characteristics of patients and the type of infection are pivotal at the time to interpret the biomarkers value. When a severe bacterial infection is clinically suspected, biomarkers have a secondary role as diagnostic tool. The decision to give antibiotics and supportive care are mainly based in the clinical features and in this scenario pro-adrenomedullin and other biomarkers could help with the diagnosis. Based on this reasoning, we think that new biomarkers included in our study could be useful not only in hospitalized patients but also in outpatients with clinically suspected serious bacterial infection as it is the case of infants with fever and toxic appearance.

Finally, as we conclude in our article: "The future usefulness of any biomarker likely depends on discovering how to combine it optimally with other clinical data".

\section{References}

1. Benito J, Luaces-Cubells C, Mintegi S, Astobiza E, Martinez-Indart L, Valls-Lafont A, García-García JJ (2013) Lack of value of midregional pro-adrenomedullin and C-terminal pro-endothelin-1 for prediction of severe bacterial infections in infants with fever without a source. Eur J Pediatr. doi:10.1007/s00431-013-2062-z

2. Oncel MY, Dilmen U, Erdeve O, Ozdemir R, Calisici E, Yurttutan S, Canpolat FE, Oguz SS, Uras N (2012) Proadrenomedullin as a prognostic marker in neonatal sepsis. Pediatr Res 72(5):507-512

J. Benito-Fernández $(\bowtie)$

Pediatric Emergency Department, Department of Pediatrics,

Cruces University Hospital, Plaza de Cruces s/n,

E-48903 Barakaldo, Bizkaia, Spain

e-mail: javier.benitof@osakidetza.net 